\title{
Investigation of Job Satisfaction and Occupational Safety Perceptions of Employees in Wastewater Treatment Plants: Study of Istanbul
}

\author{
Uçan $\mathbf{R}^{1}$, Şanlıer $\mathrm{H}^{2}$, Özay $\mathrm{ME}^{3}$ \\ ${ }^{1}$ Assistant Professor, ${ }^{2}$ Postgraduate, ${ }^{3}$ Assistant Professor \\ Uskudar University, Department of Occupational Health and Safety, Istanbul, Turkey.
}

\section{ABSTRACT}

Introduction: There exist many fatal occupational accidents in the works carried out in wastewater treatment plants.

Objectives: This research was carried out to determine the relationship between job satisfaction levels and occupational safety perceptions of employees working in wastewater treatment plants.

Methods: In this study, a questionnaire including Minnesota Job Satisfaction Scale and Occupational Safety Scale was applied to a total of 161 people aged 16-65 years working in two different Advanced Biological Wastewater Treatment Plants in Istanbul by simple random sampling. Statistical Package for Social Science version-22 was used. Seventeen hypotheses were analyzed to show relation between the occupational safety perceptions and socio-demographic parameters of employees.

Results: The results show that there is no significant relationship between job satisfaction and occupational safety perception of the personnel working in wastewater treatment plants $(F=0.096$ and $p=0.227>0.05)$. On the other hand, it is found that there is a statistically significant difference between the level of job satisfaction perception and age of the employees $(F=2.358$ and $p=0.002<0.05)$, as well as monthly income ranges $(F=4.126$ and $p=0.008$ $<0.05)$.

Conclusion: Consequently, the hazards associated with the work should be explained to employees of the wastewater treatment plant in detail. Furthermore, it is suggested to maintain an increase in wages to increase job satisfaction.

Key words: Job satisfaction, Occupational health and safety, Occupational safety perception, Wastewater treatment plant

DOI: https://doi.org/10.3126/ijosh.v10i1.29876

\section{Introduction}

The International Labor Organization (ILO) states that approximately 313 million occupational accidents occur annually worldwide and more than two million people die each year as a result of these accidents. According to the 2016 statistics of

Date of submission: 26.05 .2020

Date of acceptance: 03.07.2020

\section{Corresponding Author}

Dr. Müge Ensari Özay

Assistant Professor

Department of Occupational Health and Safety, Uskudar University

Mimar Sinan, Selmani Pak Cd, 34672 Uskudar/Istanbul

E-mail: muge.ensariozay@uskudar.edu.tr

ORCID ID: 0000-0002-4785-5503 occupational accidents in Turkey, in total 286068 insured workers have had an occupational accident, 597 insured workers got occupational diseases and 1405 people lost their lives. ${ }^{1}$ As in many sectors, there are many fatal occupational accidents in the works carried out in wastewater treatment plants. ${ }^{2}$ On November 21, 2017, an employee who worked at the wastewater treatment plant in Watertown, New York, in the USA died of an unknown cause. ${ }^{3}$ On September 11,2013 , an employee who worked in the waste water treatment plant in Canastota county of New York State died as a result of the steam boiler explosion. ${ }^{4}$

\section{(c) (1) (8)}

This journal is licensed under a Creative Commons AttributionNon Commercial 4.0 International License. 
On July 2, 2016, while two workers were performing maintenance work in a wastewater treatment plant in Amarillo, USA, they were affected by hydrogen sulfide gas and they were found unconscious by other colleagues. ${ }^{5}$ On January 31,2018 , an employee died in a waste water treatment plant in the Lothian district of Withburn, Scotland. ${ }^{6}$ On December 12, 2016, an employee who fell into a 15-meter-high wastewater treatment vessel at a waste water treatment plant in Shreveport, Louisiana, USA, died. ${ }^{7}$ Ten workers were injured as a result of an explosion at a waste water treatment plant in Chicago, USA on August 30, 2018. ${ }^{8}$

The number of wastewater treatment plants (WWTP) was 145 in 2002 in Turkey, and it increased to 653 in 2015. In addition to these facilities, the Ministry planned to construct a total of 1501 water treatment plants until 2023. ${ }^{9}$ As the number of treatment plants increases, the number of employees increases. Thus, the number of occupational risks and injuries may increase, and more detailed research will be required on occupational safety perceptions of employees.

Operation of wastewater treatment plants is quite extensive and complex. Wastewater treatment plants include one of the physical, chemical and biological processes or combinations of these to ensure the specified discharge standards and reuse wastewater. ${ }^{10}$ Because of the operation, maintenance and human factors, there are many hazards and risks in terms of occupational health and safety. Özkars evaluated the occupational risk analyzes and accident possibilities of the Sivas Wastewater Treatment Plant and showed the importance of training of employees, routine inspections and occupational safety perceptions of employees in terms of occupational safety. ${ }^{11}$ Although there exist several studies about job satisfaction and occupational awareness on different sectors, there are lack of studies about job satisfaction of waste water treatment plant employees. Rafique and Mahmood stated that more than 5,000 studies had been published on this topic. ${ }^{12}$ Lu has a review study about job satisfaction among hospital nurses. ${ }^{13}$ Ewen and coworkers have a review study about well-being and job satisfaction of pathologists. ${ }^{14}$

In this study, it is aimed to measure the job satisfaction levels of employees working in the wastewater treatment plant and to examine their occupational safety perceptions. In addition, the relationships between the demographic characteristics of the plant employees and their job satisfaction, occupational safety perception and awareness of operational hazards were also investigated.

\section{Methods}

This study was aimed to investigate the relationship between job satisfaction and occupational safety perception of the personnel working in wastewater treatment plants. The research was carried out in cross-sectional type between November 17, 2018 and December 7, 2018 in two different Advanced Biological Waste Water Treatment Plants in Istanbul. A total of 250 employee are working in both treatment plants. The position of employees in the facilities are system operators, electrical engineers, electric technician, chemist, chemical engineer, chemistry technician, environmental engineer, laboratory manager, laboratory analysis supervisor, site supervisors and office workers (accounting, human resources and administrative affairs). The sample of the research consisted of a total of 163 personnel, 105 employees in one of the Advanced Biological Waste Water Treatment Plant and 58 employees in the other. The survey of 2 people was considered invalid because they could not fill the questionnaires completely. Simple random sampling method was used. The necessary permission was obtained from the Istanbul Metropolitan Municipality of iSKi General Directorate Department of Wastewater Treatment on 09/10/2018. The purpose and content of the research was explained to the employees working in the plant and the application was carried out with the workers who wanted to participate in the research. The inclusion criteria were working full time in wastewater treatment plant, and volunteering to participate in the survey. The exclusion criterion was incomplete questionnaire.

\section{Data Collection}

In this research, data was collected using a questionnaire consisting of four parts. The first part of the questionnaire consisting of six questions was aimed to measure the demographic characteristics of the employees (gender, age, education level, marital status, monthly income, professional experience). In the second part, the Minnesota job satisfaction questionnaire (20 questions) was used to measure the job satisfaction levels of the workers. In the third part of the questionnaire, an occupational safety awareness questionnaire (8 questions) prepared by authors was used to measure employees' awareness of operational hazards in the workplace environment. In the last 
section, the occupational safety scale (32 questions) was used to measure the employees' occupational safety perceptions. All of the questions except demographic features were followed by 5 -point Likert scale. The analysis of the data was carried out with the Statistical Package of Social Science 25 (SPSS) version 22

One Sample Kolmogorov-Smirnov test was used to analyze the normality of the marital status, age, education, monthly income level and professional experience of employees working in the wastewater treatment plant with the perception of occupational safety, the level of job satisfaction and operational hazards. It was seen that the distributions are normal. Thus, independent sample t-test was used to compare quantitative continuous data between two independent groups, and One-Way Analysis of Variance was used to compare quantitative continuous data between more than two independent groups. Correlation analysis was also conducted to determine the relationships between the quantitative variables of the research.

Minnesota job satisfaction questionnaire was developed to measure the levels of job satisfaction of employees by Weiss et al. and translated into Turkish by Baycan. ${ }^{15,16}$ It is a 5 -point Likert type scale with 20 questions to identify the internal and external job satisfaction factors. The scale consists of the points of internal satisfaction, external satisfaction and general satisfaction. In the research, general satisfaction point will be evaluated. The overall satisfaction score is obtained by dividing the total score of the all items by 20. The neutral satisfaction score for the scale is 3 . If the score obtained from the scale is greater than 3 , job satisfaction is considered high. If the score obtained is less than 3 , job satisfaction is considered low.

The occupational safety awareness questionnaire ${ }^{17}$ was used to measure employees' awareness of operational hazards in the workplace environment. The questionnaire has 8 questions and has five Likert type, strongly disagree (1), disagree (2), Neutral (3), agree (4) and strongly agree (5) and evaluates employees' awareness of operational hazards in a single factor.

The occupational safety scale, which was developed by Williamson et al. ${ }^{18}$ and which was tested for validity and reliability by adapting into Turkish by Atay ${ }^{28}$ was used in order to measure the occupational safety perceptions of the wastewater plant employees participating in the research. There were 32 questions in total on the scale that has five Likert type, strongly disagree (1), disagree (2), Neutral (3), agree (4) and strongly agree (5) and evaluates employees' perceptions of occupational safety in a single factor.

\section{Results}

The data regarding the demographic characteristics of the employees participating in the research at the wastewater treatment plant is given in Table 1. The results show that $95 \%(n=153)$ of the participants are men, the age range of $36-50$ years is $47.2 \%(n=76)$, $64.6 \%(n=104)$ of employees have education level as high school, $79.5 \%(n=128)$ are married and $78.9 \%$ $(n=127)$ have monthly income between 3000-4000 TL.

Distribution of the participants according to their working experience is shown in Figure 1. The majority of the participants, $46.0 \%(n=74)$ have working experience between $5-10$ years and $23.6 \%$ of them are working more than 11 years in the wastewater treatment plant.

The results of the analysis of the hypotheses are given in Table 2. In the research, 17 hypotheses were analyzed according to SPSS results and 5 hypotheses were accepted. Since the distributions are normal, independent sample $t$ tests and One-Way Analysis of Variance were applied to the hypothesis. Hypotheses were accepted or rejected as shown in Table 2 according to their statistical significance in order to determine the job satisfaction levels and occupational safety perceptions of employees differ according to the parameters.

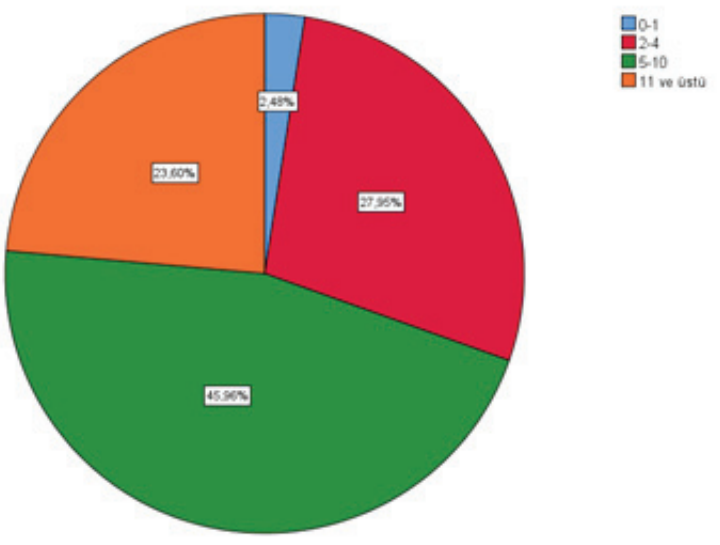

Figure 1: Distribution of the participants according to their working experience in the sector 
Uçan R et al.

Table 1: Data on demographic characteristics

\begin{tabular}{|c|c|c|}
\hline Age Range & $\mathbf{N}$ & Percentage (\%) \\
\hline $16-25$ & 7 & 4.3 \\
\hline $26-35$ & 75 & 46.6 \\
\hline $36-50$ & 76 & 47.2 \\
\hline $51-65$ & 3 & 1.9 \\
\hline Educational Status & $\mathbf{N}$ & Percentage (\%) \\
\hline Primary School & 4 & 2.5 \\
\hline Secondary School & 20 & 12.4 \\
\hline High School & 104 & 64.6 \\
\hline University & 29 & 18.0 \\
\hline Post Graduate & 4 & 2.5 \\
\hline Marital Status & $\mathbf{N}$ & Percentage (\%) \\
\hline Married & 128 & 79.5 \\
\hline Single & 33 & 20.5 \\
\hline Monthly Income & $\mathbf{N}$ & Percentage (\%) \\
\hline 2000-3000も & 17 & 10.6 \\
\hline 3000-4000 も & 127 & 78.9 \\
\hline 4000 も and above & 17 & 10.6 \\
\hline Work Experience & $\mathbf{N}$ & Percentage (\%) \\
\hline $0-1$ & 4 & 2.5 \\
\hline $2-4$ & 45 & 28.0 \\
\hline $5-10$ & 74 & 46.0 \\
\hline 11 and above & 38 & 23.6 \\
\hline
\end{tabular}

Table 2: Hypothesis analysis table

\begin{tabular}{|c|c|c|c|}
\hline Hypotheses & Variables & Results of statistics & $\begin{array}{c}\text { Acceptance (A) / } \\
\text { Rejection (R) }\end{array}$ \\
\hline Hypothesis 1 & $\begin{array}{l}\text { Occupational safety perception vs. marital } \\
\text { status }\end{array}$ & $\begin{array}{c}\mathrm{F}=0.837 \text { and } \mathrm{p}=0.404 \\
>0.05\end{array}$ & $\mathrm{R}$ \\
\hline Hypothesis 2 & Occupational safety perception vs. age & $F=1.142$ and $p=0.334>0.05$ & $\mathrm{R}$ \\
\hline Hypothesis 3 & $\begin{array}{l}\text { Occupational safety perception vs. educational } \\
\text { status }\end{array}$ & $\begin{array}{c}\mathrm{F}=0.551 \text { and } \mathrm{p}=0.698 \\
>0.05\end{array}$ & $\mathrm{R}$ \\
\hline Hypothesis 4 & $\begin{array}{l}\text { Occupational safety perception vs. monthly } \\
\text { income }\end{array}$ & $\begin{array}{c}\mathrm{F}=0.550 \text { and } \mathrm{p}=0.578 \\
>0.05\end{array}$ & $\mathrm{R}$ \\
\hline Hypothesis 5 & $\begin{array}{l}\text { Occupational safety perception vs. } \\
\text { professional experience }\end{array}$ & $\begin{array}{c}\mathrm{F}=0.778, \text { and } \mathrm{p}=0.508 \\
>0.05\end{array}$ & $\mathrm{R}$ \\
\hline Hypothesis 6 & $\begin{array}{l}\text { Occupational safety perception vs. job } \\
\text { satisfaction level }\end{array}$ & $F=0.096$ and $p=0.227>0.05$ & $\mathrm{R}$ \\
\hline Hypothesis 7 & Job satisfaction level vs. marital status & $F=1.517$ and $p=0.131>0.05$ & $\mathrm{R}$ \\
\hline Hypothesis 8 & Job satisfaction level vs. age & $F=2.358$ and $p=0.002<0.05$ & A \\
\hline Hypothesis 9 & Job satisfaction level vs. educational status & $F=1.354$ and $p=0.253>0.05$ & $\mathrm{R}$ \\
\hline Hypothesis 10 & Job satisfaction level vs. monthly income & $F=4.126$ and $p=0.008<0.05$ & $A$ \\
\hline Hypothesis 11 & Job satisfaction level vs. work experience & $F=2.164$ and $p=0.004<0.05$ & A \\
\hline Hypothesis 12 & $\begin{array}{l}\text { Awareness of operational hazards vs. marital } \\
\text { status }\end{array}$ & $F=0.528$ and $p=0.598>0.05$ & $\mathrm{R}$ \\
\hline Hypothesis 13 & Awareness of operational hazards vs. age & $\begin{array}{c}\mathrm{F}=2.037 \text { and } \mathrm{p}=0.111 \\
>0.05)\end{array}$ & $\mathrm{R}$ \\
\hline Hypothesis 14 & $\begin{array}{l}\text { Awareness of operational hazards vs. } \\
\text { educational status }\end{array}$ & $F=1.943$ and $p=0.106>0.05$ & $\mathrm{R}$ \\
\hline
\end{tabular}




\begin{tabular}{llll} 
Hypothesis 15 & $\begin{array}{l}\text { Awareness of operational hazards vs. monthly } \\
\text { income }\end{array}$ & $\mathrm{F}=2.669$ and $\mathrm{p}=0.050<0.05$ & $\mathrm{~A}$ \\
\hline Hypothesis 16 & $\begin{array}{l}\text { Awareness of operational hazards vs. work } \\
\text { experience }\end{array}$ & $\mathrm{F}=0.105$ and $\mathrm{p}=0.957>0.05$ & $\mathrm{R}$ \\
\hline Hypothesis $17 \begin{array}{l}\text { Awareness of operational hazards vs. } \\
\text { operational risk }\end{array}$ & $\mathrm{F}=0.260$ and $\mathrm{p}=0.001<0.05$ & $\mathrm{~A}$ \\
\hline
\end{tabular}

\section{Discussion}

Hypothesis (H1). Is there a significant difference between occupational safety perception and marital status?

It is found that there is no significant difference between occupational safety perception and marital status of employees. These results show similarities with the research conducted in different enterprises in Turkey. ${ }^{19}$, 20-24 Contrary to the findings of this research, another study among healthcare workers in a public hospital in Burdur, showed that the perception of security climate varies significantly according to the marital status. ${ }^{25}$

H2. Is there a significant difference between occupational safety perception and age?

There is no significant relationship between occupational safety perception and age. In line with our research findings, no significant difference was found between the age groups and the occupational safety perception as Uslu ${ }^{20}$ among the employees working in the metal industry in Eskişehir, by Kılıç ${ }^{19}$ among healthcare workers, by Çalışır ${ }^{26}$ among the employees working in the shipyard, and by Gündüz ${ }^{22}$ among the employees of Gebze Organized Industrial Zone. Furthermore, another study conducted by Bergheim et $\mathrm{al}^{27}$ on workers working in a maritime company in Norway, showed that there is no significant relationship between occupational safety perception and age. However, in some scientific studies, it was found that the occupational safety perception varies significantly by age groups. ${ }^{24,25,28-30}$ There is an increase in the ability to predict the outcome of the work in direct proportion with the increase in the experience as well age of employee to see or feel the dangers beforehand and to see or feel the dangers beforehand. With this situation, it is expected that older employees will increase their probability of displaying a more confident and safer attitude. ${ }^{31}$

H3. Is there a significant difference between occupational safety perception and educational level?
In this study, no significant difference is found between occupational safety perception and education level, similar results are seen in the literature. ${ }^{22,32}$ However, contrary to our findings in the literature, it has been found that the perception of occupational safety culture differs according to the educational status and the perception of occupational safety culture increased with the level of education. ${ }^{19,20,21}$ As the education level and the attitude of skilled workers increase, their occupational safety perception levels are expected to be higher than the other employees.

H4. Is there a significant difference between occupational safety perception and monthly income?

No significant relationship is found between the occupational safety perception and monthly income of the plant employees. Similar to our research findings, no significant difference was found in the studies conducted by Özkurt and Üzüm as well as Saraç. ${ }^{33,23}$ Contrary to our research findings, in the research conducted on employees working in the forest industry, a significant difference was found between work security perception and monthly income. It was concluded that the occupational security perception decreased with the decline in monthly income. ${ }^{21}$

H5. Is there a significant difference between occupational safety perception and professional experience?

According to the results of the study, there is no significant difference between the occupational safety perceptions and professional experience of the plant employees. Similar to the research findings, there was no significant difference between experience and occupational security perception in the literature studies. ${ }^{20,22,23}$ Contrary to our findings, in a study conducted among healthcare workers, a negative, weak and significant relationship was found between the occupational safety perception and work experience. ${ }^{19}$ In another study, it has been shown that as the experience of the workers increases, their occupational safety perceptions increase. ${ }^{34}$ Another 
study on the forest industry showed that there is a significant relationship between the occupational safety perception and professional experience, and that the employees who is working between 1-5 years have higher occupational safety perception. ${ }^{21}$ Similarly, Johnson ${ }^{35}$, Gürbüz and İbrakovic ${ }^{32}$ found that there is a significant difference between the occupational safety perceptions and the professional experience in their research.

H6. Is there a significant difference between job satisfaction level and occupational safety perception?

In this study, no significant relationship is found between job satisfaction and occupational safety perceptions of plant employees. In other words, a linear relationship cannot be mentioned between the job satisfaction and the occupational safety perceptions of the employees working in the wastewater treatment plant. In the literature, contrary our findings, a positive and strong relationship between job satisfaction and occupational security perception is found. ${ }^{36,37,38,39,40,41,42}$

H7. Is there a significant difference between job satisfaction level and marital status?

It is found that there is no significant difference between the job satisfaction level and marital status of the plant employees. Similar to our findings, Ergin ${ }^{43}$ and Kılıç ${ }^{44}$ did not find any significant results in the marital status that affects job satisfaction. Unlike the results found in our research, a study conducted by Yeter and Demirli ${ }^{45}$ on the job satisfaction of women workers, showed that the job satisfaction of female employee is high.

H8. Is there a significant difference between job satisfaction level and age?

It is found that there is a significant difference between the job satisfaction level and ages of the plant employees. Similar to our research findings; a study of Tekir et al. among health workers, showed that job satisfaction is higher at older ages and stated that similar situation is also observed in studies conducted in Pakistan and Japan. ${ }^{46}$ As a result, it is seen that the increase in experience and job satisfaction is directly proportional.

H9. Is there a significant difference between job satisfaction level and educational level?

According to the results, there is no significant difference between the job satisfaction level and educational level of the plant employees. Contrary to our research findings; in some studies, it was found that higher educated people had higher job satisfaction. ${ }^{45,47,48,49}$

H10. Is there a significant difference between job satisfaction level and monthly income?

An important result of the study is that there is a significant difference between job satisfaction level and monthly income of the plant employees. Similar to our research findings, Unal found that there is a positive relationship between income level and job satisfaction. ${ }^{50}$ As another similar research result, Kılıç stated that wage is one of the important factors affecting job satisfaction of teachers. ${ }^{44}$

H11. Is there a significant difference between job satisfaction level and work experience?.

There is a significant difference between the job satisfaction level and work experience of the employees. Similar to our research results, Kılıç stated that professional experience is among the factors that affect job satisfaction in his study on teachers. ${ }^{44}$ As the seniority of the teachers increases, they do not see the current problems and negativities as problems, and their job satisfaction increases as they progress in the profession. ${ }^{44}$

H15. Is there a significant difference between employees' awareness of operational hazards and monthly income?

Another important result is that there is a significant difference between plant employees' awareness of operational hazards and monthly income. There is a strong positive relationship between the employees' awareness of operational hazards and their occupational safety perceptions. In other words, as the awareness of the operational hazards of the plant employees increases, their occupational safety perception becomes stronger.

\section{Conclusion}

Consequently, there is a positive relationship between age and job satisfaction; job satisfaction and monthly income, job satisfaction and professional experience; awareness of operational hazards and income level, awareness of operational hazards and occupational safety perception. In addition, it is found that there was no significant relationship between job satisfaction and occupational security perception. In other words, a linear relationship cannot be mentioned between the job satisfaction and the occupational safety perception 
of the employees in the wastewater treatment plant.

Two important conclusions are proposed to this research. Firstly, the occupational safety perception increases with the knowledge of the hazards existing in the treatment plant. It is suggested to explain the hazards about ongoing work in maximum detail to the employees in order to increase the awareness of the workers. Periodic occupational health and safety educations are recommended from the beginning of the job. Workers should be made aware and educated

\section{References}

1. Kavgacı Y. The effect of occupational health and safety practices on employee performance in hospital enterprises: Case of association of public hospitals in Burdur [master's thesis]. Mehmet Akif Ersoy University; 2018.

2. Demir E. Investigation of the relationship between construction workers' job satisfaction levels and safety perceptions [master's thesis]. Uskudar University; 2018.

3. Processing Magazine [Internet]. 2013[Assessed on 2019/10/07]. Available at: https://www. processingmagazine.com/explosion-at-wastewatertreatment-plant-kills-worker/

4. Texomas [Internet]. 2016[Assessed at 2019/10/07. Available at: https://www.texomashomepage.com/ news/city-releases-investigation-findings-of-treatmentplant-accident/

5. BBC News [Internet]. 2018[Assessed at 2019/10/07. Available at: https://www.bbc.com/news/uk-scotlandedinburgh-east-fife-42891041

6. Water and Wastes Digest [Internet]. 2006[Assessed at 2019/10/07. Available at: https://www.wwdmag.com/ worker-dies-wastewater-treatment-plant-accident

7. Environmental Science and Engineering Magazine [Internet]. 2018[Assessed at 2019/10/07. Available at: https://esemag.com/wastewater/explosions-at-uswater-and-wastewater-plants-injure-workers/

8. Republic of Turkey Ministry of Environment and Urbanization [Internet]. 2016[Assessed at 2018/12/28. Available at: https://cygm.csb.gov.tr/bakanlik-2023-yiliatık su-aritimi-eylem-planini-hazirladi-duyuru-55407

9. Weiss DJ, Dawis RV, England GW, Lofquist LH. Manual for the Minnesota Satisfaction Questionnaire. USA: University of Minnesota; 1967.

10. Güner E. Environmental risk assessment for biological wastewater treatment plant. Pamukkale University Journal of Engineering Sciences. 2018; 24(3): 476-80.

11. Özkars R, Yıldız S. Evaluation of occupational health and safety conditions of wastewater treatment plant in Turkey. Erciyes University Journal of the Institute of Science and Technology. 2013; 29(3): 254-61. regarding the hazards and the safety measures so that many accidents may be prevented. Secondly, the increase in the income level causes increase in job satisfaction positively. It is suggested to maintain an increase in wages to increase job satisfaction.

\section{Conflict of Interest}

The author(s) declared no potential conflicts of interest with respect to the research, authorship, and/or publication of this article.

12. Rafique GM, Mahmood K. Relationship between knowledge sharing and job satisfaction: a systematic review. Information and Learning Science. 2018; 119(5-6):295-312.

13. Lu H, Zhao $\mathrm{Y}$, While A. Job satisfaction among hospital nurses: A literature review International Journal of Nursing Studies. 2019; 94:21-31.

14. Ewen C, Jackson C, Galvin J, Jenkins H, Jutley-Neilson $\mathrm{J}$. Well-being, job satisfaction, stress and burnout in speech-language pathologists: A review. International Journal of Speech-Language Pathology. 2020.

15. Baycan A. An Analysis of Several Aspect of Job Satisfaction Between Different Occupational Groups [master's thesis]. Boğaziçi University; 1985.

16. Kılıç T. Determination of the Perception of Occupational Safety of Healthcare Workers Working in a Training and Research Hospital [master's thesis]. Türk Hava Kurumu University; 2014.

17. Şanlıer H. Measuring job satisfaction of employees in wastewater treatment plants and investigation of their perceptions of safety [master's thesis]. Uskudar University; 2019.

18. Williamson, A.M., Feyer, A.M., Caims, D., Biancotti, D. The development of a mesure of safety climate: The role of safety perceptions and attitudes. Safety Science, 1997, 25(1-3):15-27.

19. Uslu V. The relationship between work safety performance and safety culture perceptions in enterprises: A research in the metal sector in Eskişehir province [master's thesis]. Eskişehir Osmangazi University; 2014.

20. Aydın A, Tiryaki S, Üçüncü K, Yıldırım İ. Perception of workplace safety climate in forest products industry. SDÜ Mühendislik Bilimleri ve Tasarım Dergisi. 2015; 3(3): 205-12.

21. Gündüz B. The relationship between employees' organizational commitment and work security perceptions: The case of Gebze organized industrial zone [master's thesis]. Nişantaşı University; 2016.

22. Saraç ÇK. Examining the relationship between the perception of occupational health and safety culture and job satisfaction [master's thesis]. Nişantaşı University; 2016. 
23. Bayraktaroğlu S, Aras M, Atay E. Occupational safety and work accident perception: a research on blue collar. Uluslararası Yönetim ve Sosyal Araştırmalar Dergisi. 2018; 15(9): 1-15.

24. Şantaş F, Şantaş G, Özer Ö, Say ŞD. Research in a public hospital on the determination of healthcare workers' perceptions of security climate. Journal of Pamukkale University Social Science Institute. 2018; 30: 297-307.

25. Çalışır S. A field study on the perception of safety in workers working in civil shipyards (Tuzla region) [master's thesis]. Nişantaşı University; 2015.

26. Bergheim K, Nielsen MB, Mearns K, Eid J. The relationship between psychological capital, job satisfaction and safety perceptions in the maritime industry. Safety Science. 2014; 74: 27-36.

27. Siu O, Phillips DR, Leung T. Age differences in safety attitudes and safety performance in Hong Kong construction workers. Journal of Safety Research. 2003; 34(2): 199-205.

28. Fang $\mathrm{D}$, Chen $\mathrm{Y}$, Wong L. Safety climate in construction industry: a case study in Hong Kong. Journal of Construction Engineering and Management. 2006; 132(6): 573-84.

29. Alkış H, Taşpınar Y. New approaches in occupational health and safety, employee health and safety perception of iron and steel industry employees: The case of Konya province. IISS12 International Iron and Steel Symposium Reports. 2012.

30. Aydın F. The effect of physical working conditions on job satisfaction in businesses [master's thesis]. Atatürk University; 2010.

31. Gürbüz $H$, İbrakovic $H$. Occupational safety, safety performance and safety culture in businesses. Sosyal Bilimler Dergisi. 2017; 4(11): 442-69.

32. Özkurt SS, Üzüm B. Approaches of students to worker health and safety (Kocaeli MYO Example). International Journal of Disciplines Economics\&Administrative Sciences Studies. 2018; 4(7): 99-111.

33. Tozkoparan G, Taşoğlu J. A research to determine the attitudes of the employees about occupational health and safety practices. Uludağ University İktisadi ve İdari Bilimler Fakültesi Dergisi. 2011; 15(1):181-209.

34. Johnson SE. The predictive validity of safety climate. Journal of Safety Research. 2007; 38(5): 511-521.

35. Atay F. Investigation of job satisfaction levels of individuals working in the field of industry in terms of occupational safety perceptions [master's thesis]. Sakarya University; 2006.

36. Nielsen MB, Mearns K, Matthiesen SB, Eid J. Using the job demands-resources model to investigate risk perception, safety climate and job satisfaction in safety critical organizations. Scandinavian Journal of Psychology. 2011; 52: 465-75.
37. Avram E, lonescu D, Mincu CL. Percived safety climate and organizational trust: the mediator role of job satisfaction. Procedia-Social and Behavioral Sciences. 2015; 187: 679-84.

38. Stoilkovska BB, Pancovska VZ, Mijoski G. Relationship of safety climate perceptions and job satisfaction among employees in the construction industry: the moderating role of age. International Journal of Occupational Safety and Ergonomics. 2015; 21(4): 440-47.

39. Yıldırım I, Akyüz KC, Akyüz I, Alevli C. Examining the job security perceptions and job satisfaction levels of the workers in the furniture industry. Selçuk-Teknik Dergisi. 2015; 171-84

40. Huang YH, Lee J, McFadden AC, Murphy LA, Robertson $\mathrm{MM}$, Cheung $\mathrm{JH}$. et al. Beyond safety outcomes: An investigation of the impact of safety climate on job satisfaction, employee engagement and turnover using social exchange theory as the theoretical framework. Applied Ergonomics. 2016; 55: 248-57.

41. Idrees MD, Hafeez M, Kim JY. Workers' age and the impact of psychological factors on the perception of safety at construction sites. Sustainability. 2017; 9: 1-15.

42. Ergin C. 'Job description scale' as a job satisfaction measurement: adaptation, validity and reliability study. Turkish Journal of Psychology. 1997; 12(39): 25-36.

43. Kılıç ÖS. Job satisfaction of school principals and teachers working in primary schools (Tokat province example) [master's thesis]. Selçuk University; 2011.

44. Yeter N, Demirli C. Examining Job Satisfaction of Working Women. The Journal of Educational Reflections. 2017; 1(1):38-50.

45. Tekir Ö, Çevik C, Arık S, Ceylan C. Examination of burnout, job satisfaction levels and life satisfaction of healthcare professionals. Kırıkkale University Tıp Fakültesi Dergisi. 2016; 18(2):51-63.

46. Seattle Times [Internet]. 2019 [Assessed at 2019/10/08. Available at: https://www.seattletimes.com/nationworld/worker-killed-in-accident-at-city-wastewatertreatment-plant/

47. Anar B. Examining the Relationship between Gender Roles of Married and Working Adults and Marriage Satisfaction and Job Satisfaction [master's thesis]. Çukurova University; 2011.

48. Kahraman G. Job satisfaction of intensive care nurses and affecting factors. Dokuz Eylül University Hemşirelik Yüksekokulu Elektronik Dergisi. 2011; 4(1):12-8.

49. Kaya F. Job satisfaction and affecting factors in primary health care professionals in Elazig province [master's thesis]. Fırat University; 2013.

50. Ünal F. Relationship between Emotional Labor and Job Satisfaction and Alienation to Work; A Qualitative Research on Bank Employees [master's thesis]. Süleyman Demirel University; 2018. 